\title{
Assessment of Candidal carriage in patients with Type II Diabetes Mellitus
}

\author{
Lamichhane $\mathrm{RS}^{1}$, Boaz K${ }^{2}$, Natarajan $\mathrm{S}^{2}$, Shrestha $\mathrm{M}^{3}$ \\ ${ }^{I}$ Department of Oral and Maxillofacial Pathology, Kist Medical College, Lalitpur, Nepal \\ ${ }^{2}$ Department of Oral and Maxillofacial Pathology and Oral Microbiology, Manipal college of Dental Surgery, Mangalore, India \\ ${ }^{3}$ Department of Oral and Maxillofacial Pathology, Chitwan Medical College Teaching Hospital, Bharatpur, Nepal
}

\section{Keywords: \\ Diabetes Mellitus; \\ Candida; \\ Candidal carriage}

\begin{abstract}
Background: It is generally acknowledged that patients with diabetes mellitus are more susceptible to fungal infections, particularly with Candida albicans. Oral infection by Candida can result in a number of clinical lesions, including median rhomboid glossitis (central papillary atrophy), denture stomatitis, squamous cell carcinoma, Radiation therapy, immunocompromised status, etc. Different studies have shown that patients with diabetes mellitus have increased frequency of oral candidal carriage and increased risk of candidiasis, which is related to poor metabolic control, neutrophil dysfunction, reduced salivary flow, high glucose concentration in blood and saliva and in medications.
\end{abstract}

Materials and Methods: Subjects of both the groups were given $10 \mathrm{ml}$ of sterile normal saline and asked to rinse the mouth for one minute. The subjects were then asked to return the oral rinse in a sterile clean, broad-mouthed container which was capped, labelled and taken to the laboratory. The samples were then inoculated onto the culture medium (Sabouraud's dextrose agar with Chloramphenicol) with minimal delay (within 6-8 hours of collection of oral rinse). Candidal colonies were counted and compared with non-diabetics.

Results: Statistically significant increase in colony forming units $(p=0.0324)$ were obtained in patients with diabetes mellitus.

Conclusion: The results indicate significant increase in colonization and carriage of candida in the oral cavity among diabetics when compared with non-diabetics. However, further research using larger samples is required which may lend credibility to the suggestion of increased candidal CFUs in diabetics serving as a surrogate marker of serum glucose levels.

\section{INTRODUCTION}

Diabetes mellitus (DM) is an ancient metabolic disorder, dating from 1500 B.C, when it was referred to for the

\section{Correspondence:}

Dr. Ram Sudhan Lamichhane, MDS

Department of Oral and Maxillofacial Pathology,

Kist Medical College, Lalitpur, Nepal

E-mail:drramsudhan@gmail.com first time in the Egyptian papyrus Ebers as 'a disease accompanied by polyuria, demanding due treatment'.

Diabetes mellitus designates a group of metabolic diseases characterized by hyperglycemia due to insufficient insulin secretion and/or reduced insulin sensitivity, and associated with abnormal metabolism of glucose, lipid and protein. The chronic hyperglycaemia leads to an increased risk of 
developing microangiopathy, accelerated atherosclerosis, neuropathy and impaired wound healing. ${ }^{1-3}$

The main complications associated with diabetes mellitus are retinopathy, neuropathy, nephropathy and macro/ microangiopathy. Several studies suggest a higher prevalence and severity of some pathologies in the oral tissues of diabetes mellitus patients, like gingivitis, periodontitis, dental caries, candidiasis, and other oral manifestations such as alteration of salivary flow and oral burning sensation.

It is generally acknowledged that patients with diabetes mellitus are more susceptible to fungal infections, particularly with Candida albicans. ${ }^{4}$ Oral infection by Candida can result in a number of clinical lesions, including median rhomboid glossitis (central papillary atrophy), denture stomatitis, squamous cell carcinoma, Radiation therapy, immunocompromised status (HIV), etc. ${ }^{4}$ Different studies have shown that patients with diabetes mellitus have increased frequency of oral candidal carriage and increased risk of candidiasis, which is related to poor metabolic control, neutrophil dysfunction, reduced salivary flow, high glucose concentration in blood and saliva and in medications. $^{5}$

Methods to identify, quantify and establish the pathogenicity of Candida have included a number of techniques, such as smears and swabs, imprint or impression cultures, and estimates of the number of organisms by using colony counts from saliva and oral rinses. ${ }^{4}$

The present study aims to determine the candidal carriage in patients with type II diabetes mellitus as it is hypothesised that patients with type 2 DM may exhibit a certain degree of local immune suppression, thereby enabling the candidal population to proliferate beyond the levels that are normally seen when it is a commensal in the oral cavity.

\section{MATERIALS AND METHODS}

The present study was conducted in the Department of Oral Pathology and Microbiology, Manipal College of Dental Sciences, Mangalore over a period of 12 months from January 2010 to January 2011. The study involved the assessment of candidal carriage using oral rinse samples.

\section{Study Sample}

The study comprised of a total of 60 subjects divided into

Table 1: Descriptive data for various parameters

\begin{tabular}{lcccccl}
\hline Parameter & Category & $\mathrm{N}$ & Minimum & Maximum & Median & $\begin{array}{l}\text { Interquartile } \\
\text { range }\end{array}$ \\
\hline $\begin{array}{l}\text { Colony } \\
\text { Forming }\end{array}$ & Cases & 30 & 0.00 & 8400 & 1020.00 & $\begin{array}{l}3405.00(240, \\
365)\end{array}$ \\
$\begin{array}{l}\text { Units } \\
\text { Controls }\end{array}$ & 30 & 0.00 & 7740 & 270.00 & $\begin{array}{l}1315.00(55, \\
1370)\end{array}$
\end{tabular}

two groups:

Study group: Consisting of thirty individuals above 40 years of age with a known history of type II diabetes mellitus for a minimum period of one year. The subjects with diabetes were selected from among the patients attending the dedicated Diabetic clinic of K. M. C. Hospital, Attavar Mangalore. Patients were included irrespective of whether they were under insulin or oral hypoglycaemic therapy for diabetes.

Control group: Consisted of thirty age and sex-matched healthy individuals without any history of diabetes mellitus (assessed by random blood sugar). ${ }^{6}$

\section{Exclusion criteria}

Patients/ individuals with the following were excluded from the study:

1. Habits of smoking or betel nut chewing.

2. Medication for systemic disease other than diabetes mellitus.

3. Known cases of malignancy.

4. Patients who have undergone radiation therapy and chemotherapy

5. Subjects with poor oral hygiene.

6. Denture wearers

\section{Inclusion criteria}

1. Patients between above 40 yrs with clinically healthy oral mucosa

2. Medical history of type II Diabetes mellitus for a minimum period of 1 year and patients irrespective of whether they were under any medication for diabetes or not.

3. Diagnostic criteria for type II diabetes mellitus were as follows: ${ }^{7}$

a. Random serum glucose concentration $>200 \mathrm{mg} / \mathrm{dl}$ (11.1mM); or

b. Fasting serum glucose level $>126 \mathrm{mg} / \mathrm{dl}$ (7.0mM); or c. 2 hour plasma glucose $>200 \mathrm{mg} / \mathrm{dl}(11.1 \mathrm{mM})$

Table 2: Assessment of variations between cases and controls using Mann Whitney $U$ test

\begin{tabular}{lcclll}
\hline \multicolumn{1}{c}{ Parameter } & Category & N & Mean Rank & Z & P Value \\
\hline $\begin{array}{l}\text { Colony Form- } \\
\text { ing Units }\end{array}$ & Cases & 30 & 35.32 & -2.139 & $\underline{0.0324}$ \\
& Controls & 30 & 25.68 & &
\end{tabular}

Table 3: Pearson's correlation between the glucose levels and morphometric parameters

\begin{tabular}{lllll}
\hline \multicolumn{1}{c}{ Parameter } & R & R2 & F & p value \\
\hline $\begin{array}{l}\text { Colony Forming } \\
\text { Units }\end{array}$ & 0.096 & 0.009 & 0.404 & 0.528 \\
\hline
\end{tabular}




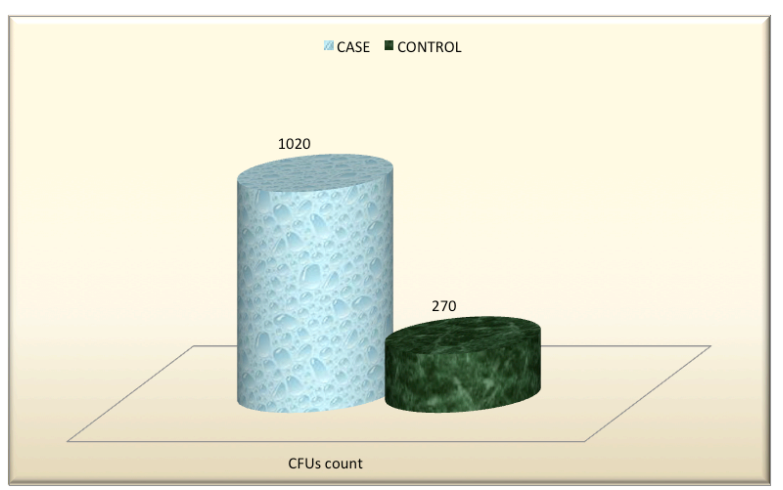

Figure 1: Indicating the distribution of colony forming units (CFUs) among cases and control.

4. Control group of volunteers having clinically healthy oral mucosa and no clinical signs of systemic diseases and positive laboratory findings (absence of diabetes)

\section{Methods of collection of Data:}

Ethical clearance was obtained from the Institutional Ethics Committee (MCODS, Mangalore). Subjects of both the study and control groups were informed of the procedure and a written consent was obtained. All the subjects were clinically examined to assess the oral hygiene and to exclude the possibility of any other oral disease or systemic disease with oral manifestations. For study groups, haematological assessment for blood glucose/glycosylated haemoglobin levels was obtained from patients' medical records.

\section{Assessment of candidal colonization:}

\section{Materials used:}

- Sterile physiological saline solution

- Disposable sterile container for sample collection

- Disposable gloves and mouth masks

- Sabouraud's dextrose agar (with Chloramphenicol)

\section{Oral Rinse Method:}

\section{An overview of the procedures:}

Subjects of both the groups were given $10 \mathrm{ml}$ of sterile normal saline and asked to rinse the mouth for one minute. The subjects were then asked to return the oral rinse in a sterile clean, broad-mouthed container which was capped, labeled and taken to the laboratory. The samples were then inoculated onto the culture medium (Sabouraud's dextrose agar with Chloramphenicol) with minimal delay (within 6-8 hours of collection of oral rinse).

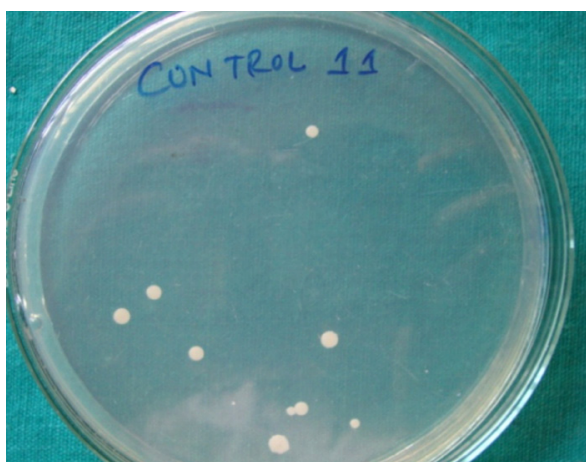

Figure 2: Smooth creamy while colonies of Candida growing on Sabouraud's Dextrose Agar (SDA) in control group.

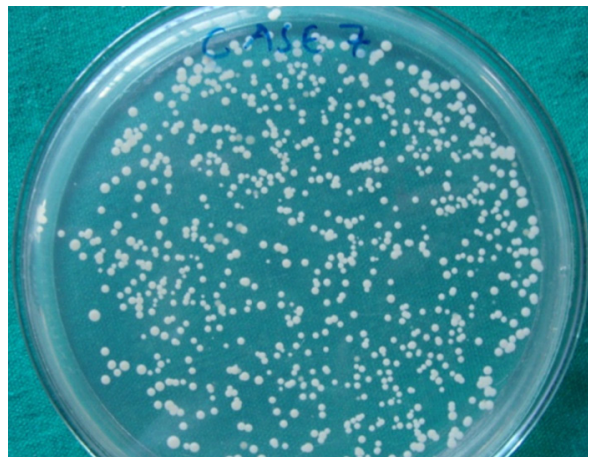

Figure 3: Smooth creamy white colonies of Candida growing on Sabouraud's Dextrose Agar (SDA) in study group of diabetic patients.

\section{Method of counting colonies:}

Fifty $\mu$ of sample was taken using micropipette and streaked onto culture plates containing Sabouraud's Dextrose Agar with Chloramphenicol and incubated at $370 \mathrm{C}$ for 48 hours. Number of colonies formed were counted and multiplied with a factor of 20 to get the colonies in $1 \mathrm{ml}$ of a subject's sample. ${ }^{8}$

Number of colonies contained in $50 \mu$ of saliva $=n$

Therefore the number of colonies in $1000 \mu \mathrm{l}(1 \mathrm{ml})$

$=\mathrm{n} \times 1000 / 50$

$=\mathrm{n} \times 20$

\section{Statistical Analysis:}

The data was analysed using SPSS software. (Version 19) Mann Whitney $U$ test was carried out to calculate CFU counts. Forward stepwise linear regression and Pearson's correlation was done to correlate various significant parameters in relation to glucose level. 


\section{INCREASE IN CANDIDA COLONIZATION IN DIABETES MELLITUS}

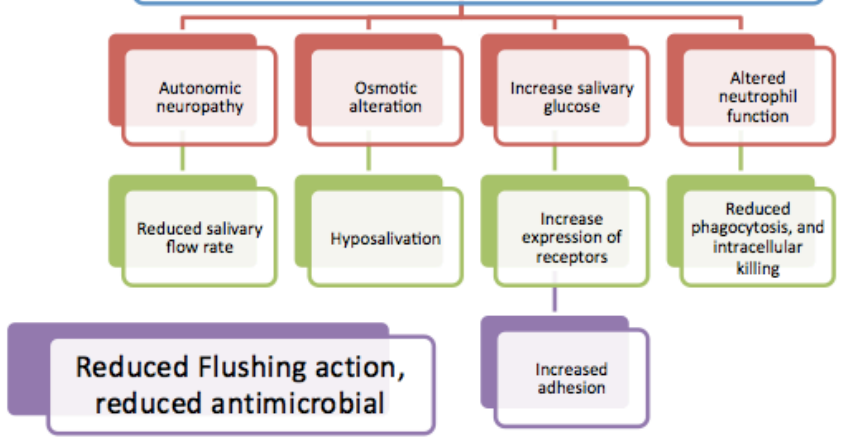

Figure 4: Depicting interrelationship between DM and Oral Candidal Colonization

\section{RESULTS}

The first table (Table. 1) showed that the total colony forming units was higher in cases (1020) than in controls (270) (fig.1).

As the data was found to follow a skewed distribution pattern, nonparametric tests were used to study the differences. Thus, Mann Whitney U test (Table. 2) was applied to assess the variations between cases and controls for each of the variables. The increase in CFU counts (median 1020) among cases was statistically significant $(\mathrm{Z}=$ $-2.139, \mathrm{p}=0.0324)$ (fig.2 \& fig.3).

Correlation of glucose level using linear regression (Table. 3) showed no correlation. The colony forming units $(0.096)$ showed no correlation.

\section{DISCUSSION}

Diabetes Mellitus (DM) is a disease affecting multiple organs and this combined with changes in the oral cavity such as xerostomia (dry mouth), alteration of taste and burning mouth sensation causes localised immune suppression thereby causing shift in homeostasis of the oral micro flora. ${ }^{8}$ Candida albicans is a commensal yeast and $40-60 \%$ of the healthy adults harbour Candida in the oral cavity. ${ }^{5}$ Candida species especially Candida albicans have been frequently isolated from the oral cavity of patients with DM and it has been reported that upto $77 \%$ of insulin-treated diabetic patients harbour oral Candida. ${ }^{9}$

Various studies have been reported in support of ${ }^{10-12}$ and against ${ }^{13-15}$ the hypothesis that "poor glycaemic control predisposes to oral candidal infection in diabetic patients". A study carried out by Aly et al ${ }^{9}$ and Hill et al ${ }^{12}$ found that oral carriage of yeasts was associated with increased plasma glucose levels $(\mathrm{P}<0.05)$ and concluded that poor glycaemic control was a significant contributory factor in palatal carriage of yeasts in patients with Type $2 \mathrm{DM}(\mathrm{P}<0.01)$. Also a study by Sashikumar R and Kannan $\mathrm{R}^{11}$ found a significant correlation between the salivary glucose level and the blood glucose level in diabetic subjects and hence proposed that increased blood glucose level increases the salivary glucose level and this increase, likely contributes to increased yeast carriage and the potential for increased susceptibility to oral candidiasis.

Another study using an oral rinse technique for estimation of oral candidal carriage found no difference between the patients of Types 1 and 2 DM. Furthermore, the frequency of isolation and oral candidal load were not influenced either by duration or type of diabetes, glycated haemoglobin level or diabetic complications. ${ }^{9}$

Candidal carriage in DM is rendered non-comparable by the use of different methods like swabs, smears, imprint, oral rinse etc for the recovery of Candida from the oral cavity. ${ }^{16,17}$ The oral rinse technique using normal saline is known to be a sensitive technique mainly because, the entire oral cavity is sampled in a single rinse thereby ensuring coverage of greater surface area. ${ }^{17}$

In the present study, a comparison of oral candidal carriage between the study group of diabetics and the control group of non-diabetics showed significant increase $(p=0.0324)$ in the colony forming units (CFUs) of Candida ranging from 0 to $8400 \mathrm{CFU} / \mathrm{ml}$ of saliva with the median of 1020 while in non-diabetics, the candidal counts ranged from 0 to $7740 \mathrm{CFU} / \mathrm{ml}$ with the median of 270 . This result is in accordance with previous studies, which had also reported greater prevalence of Candidal carriage in the oral cavity of diabetics than in normal subjects. . $^{11,13-15,18-20}$ However, Loiselle et al and Peter et al found no difference in the frequency of isolation of Candida organism from the oral cavities of diabetics and non-diabetics. ${ }^{19}$

The increased oral candidal carriage load may be attributed to hyposalivation, increased salivary glucose and/or altered neutrophil function (fig.4). The increased salivary glucose concentration may form chemically reversible glycosylation products with proteins in tissues during hyperglycaemic episodes. It is possible that accumulation of such glycosylation products on epithelial cells may increase the number of available receptors for Candida. ${ }^{9}$ Observations made by Darwazeh et $\mathrm{al}^{21}$ where the adhesion of Candida albicans to Buccal Epithelial Cells (BEC) from 50 diabetic patients was $55 \%$ higher than the cells from 50 age- and sex-matched non-diabetic control subjects ( $\mathrm{P}$ $<0.001$ ) supports this theory. These results agree with a study by Dorocka-Bobkowska et $\mathrm{al}^{22}$ who reported that the mean candidal adherence to palatal epithelial cells (PEC) of diabetic patients was 34.5 yeasts/PEC versus 20.7 yeasts/ 
PEC for control subjects $(\mathrm{P}<0.001)$.

The other important manifestation in diabetics that could lead to high oral candidal carriage is hyposalivation. ${ }^{8}$ Dehydration associated with elevated blood glucose increases osmotic gradients within the salivary glands, thereby limiting secretion. ${ }^{10,23}$ Autonomic neuropathies that diminish the ability of salivary glands to respond to a salivary stimulus or microvascular changes that compromise the ability of salivary glands to respond to neural or hormonal stimulation in diabetic patients could explain the significantly lower salivary flow rates in diabetics. ${ }^{10,23}$ Hyposalivation therefore compromises both the flushing and antimicrobial action of saliva. Also saliva possesses secretory immunoglobulin A ( $\operatorname{Ig} \mathrm{A})$ and free secretory component (SC) which normally inhibit Candidal adhesion to oral epithelial cells. Thus, hyposalivation leads to imbalance of the normal homeostatic mechanism that otherwise ward off candidal infections. ${ }^{9}$

Another host factor which may promote the oral carriage of Candida in diabetes is the possible defects in candidacidal activity of neutrophils, particularly in the presence of glucose. For instance, when the Candida killing ability was correlated with the production of superoxide, the polymorphonuclear leucocytes (PMN) from diabetic patients with candidiasis produced less free oxygen radicals and exhibited reduced phagocytosis and intracellular killing of Candida. Hence, decreased phagocytosis, intracellular killing, bactericidal activity and chemotaxis associated particularly with poorly controlled diabetes may render the diabetic patient more prone to candidal infection. ${ }^{9}$

Candidal infection in diabetics is thus a reflection of neural, hormonal and immunological status of an individual and the emphasis should be on a holistic approach to management of diabetes mellitus. The present study compared oral candidal carriage between the study group of diabetics and the control group of non-diabetics with results of a significant increase in the CFU count of diabetics. Therefore, our study, while limited in its sample size, suggests that oral candidal carriage can also serve as a surrogate marker of serum glucose levels, enabling non-invasive periodic evaluation of serum glucose levels.

\section{CONCLUSION}

Oral rinses obtained from the study and control groups showed significant increase in Colony Forming Units of Candida albicans among diabetics when compared to nondiabetics.

The increase in candidal colony counts in diabetics may be explained as:

1. Higher salivary glucose levels in diabetic patients favour yeast growth.

2. Accumulation of increased glycosylation products on oral epithelial cells of diabetic patients may increase the number of available receptors for Candida.

3. Hyposalivation secondary to neuropathy in diabetics may enhance candidal colonization as the normal anti-fungal properties of saliva stand diminished.

4. Possible defects in candidacidal activity of neutrophils, particularly in the presence of elevated levels of glucose.

The results indicate significant increase in colonization and carriage of candida in the oral cavity among diabetics when compared with non-diabetics. However, further research using larger samples is required which may lend credibility to the suggestion of increased candidal CFUs in diabetics serving as a surrogate marker of serum glucose levels.

\section{REFERENCES}

1. 1. Alberti KG, Zimmet PZ. Definition, diagnosis and classification of diabetes mellitus and its complication. Part 1: diagnosis and classification of diabetes mellitus provisional report of a WHO consultation. Diabet Med 1998;15:539-553. Crossref

2. Skamagas M, Breen TL, LeRoith D. Update on diabetes mellitus: prevention, treatment, and association with oral diseases. Oral Diseases 2008;14:105-114. Crossref

3. World Health Organisation report on definition, diagnosis and classification of diabetes mellitus and its complications. Geneva: WHO 1999 page 1-2.

4. Jones AC, Pink FE, Sandow PL, Stewart CM, Baughman RA. The Cytobrush Plus cell collector in oral cytology. Oral Surg Oral Med Oral Pathol 1994;77:101-104. Crossref

5. Mehrotra R, Hullmann M, Smeets R, Reichert TE, Driemel O. Oral cytology revisited. J Oral Pathol Med 2009;38:161-166. Crossref

6. Prasad H, Ramesh V, Balamurali PD. Morphologic and cytomorphometric analysis of exfoliated buccal mucosal cells in diabetes patients. Journal of Cytology 2010 October;27:113-117. Crossref

7. Powers Alvin C. Diabetes Mellitus, Harrison's Principles of Internal Medicine. 16th Edition Volume II, pp 2152-8.

8. Belazi M, Velegraki A, Fleva A, Gidarakou I, Papanaum L, Baka $\mathrm{D}$, Daniilidou $\mathrm{N}$ et al. Candidal overgrowth in diabetic patients: potential predisposing factors. Mycoses 2005,48,192-196. Crossref

9. Soysa NS, Samaranayake LP and Ellepola A.N.B. Diabetes mellitus as a contributory factor in oral candidosis. Diabetes Medicine 2005;23:455-459. Crossref

10. Guggenheimer J, Moore PA, Rossie K, Myers D, Mongelluzzo MB, Block HM et al. Insulin-dependent diabetes mellitus and oral soft tissue pathologies II. Prevalence and characteristics of Candida and candidal lesions. Oral Surg Oral Med Oral Pathol Oral Radiol Endod 2000;89:570-576. Crossref

11. Sashikumar R, Kannan R. Salivary glucose levels and oral candidal carriage in type II diabetics. Oral Surg Oral Med Oral Pathol Oral Radiol Endod 2010;109:706-711. Crossref

12. Hill LVH, Tan MH, Pereira LH, Embil JA. Association of oral candidiasis with diabetic control. J Clin Pathol 1989;42(5):502-505. Crossref

13. Fisher BM, Lamey P-J, Samaranayake LP, MacFarlane TW, Frier BM. Carriage of Candida species in the oral cavity in diabetic patients: relationship to glycaemic control. J Oral Pathol 1987;16:282-284. Crossref 
14. Willis AM, Coulter WA, Fulton CR, Hayes JR, Bells PM, Lamey P-J. Oral candidal carriage and infection in insulin-treated diabetic patients. British Diabetic Association. Diabetic Medicine 1999;16:675-679. Crossref

15. Kumar BV, Padshetty NS, Bai KY, Rao MS. Prevalence of Candida in the Oral Cavity of Diabetic subjects. JAPI 2005;53:599-603.

16. Samaranayake Lakshman P, MacFarlane T. Wallace. Methods of isolation of Candida from oral cavity, Oral Candidosis. London: Wright, 1990. pp 25-27.

17. Samaranayake LP, MacFarlane TW, Lamey P-J, Ferguson MM. A comparison of oral rinse and imprint sampling techniques for the detection of yeast, coliform and Staphylococcus aureus carriage in the oral cavity. J Oral Pathol 1986;15:386-388. Crossref

18. Bhatt GH, Doshi JJ, Bilimoria KF. Candida in the oral cavity of Diabetics and Nondiabetics. Journal Indian Dent. Asso. 1983;55:367369.

19. Lamey P-J, Darwaza A, Fisher BM, Samaranayake LP, MacFarlane TW, Frier BM. Secretor status, candidal carriage and candidal infection in patients with diabetes mellitus. J. Oral Pathol 1988;17:354-357. Crossref

20. Abu-Elteen KH, Hamad MA, Salah SA: Prevalence of Oral Candida Infections in Diabetic Patients. Bahrain Med Bull 2006;28:1-6.

21. Darwazeh AMG, Lamey P-J, Samaranayake LP, MacFarlane TW, Fisher BM, Macrury SM et al. The relationship between colonisation, secretor status, and in-vitro adhesion of Candida albicans to buccal epithelial cells from diabetics. J Med. Microbiol. 1990;33:43-49. Crossref

22. Dorocka-Bobkowska B, Budtz-Jorgensen E, Wloch S. Non-insulin dependent diabetes mellitus as a risk factor for denture stomatitis. $\mathrm{J}$ Oral Pathol Med 1996;25:411-415. Crossref

23. Moore PA, Guggenheimer J, Etzel KR, Weyant RJ, Orchard T. Type 1 diabetes mellitus, xerostomia, and salivary flow rates. Oral Surg Oral Med Oral Pathol Oral Radiol Endod 2001;92:281-291. Crossref 